\title{
Nelumbo nucifera leaves extracts inhibit mouse airway smooth muscle contraction
}

\author{
Xiao Yang ${ }^{\dagger}$, Lu Xue ${ }^{\dagger}$, Qingyang Zhao ${ }^{1}$, Congli Cai ${ }^{2}$, Qing-Hua Liu ${ }^{1 *}$ and Jinhua Shen ${ }^{1 *}$ (D)
}

\begin{abstract}
Background: Alkaloids extracted from lotus leaves (AELL) can relax vascular smooth muscle. However, whether AELL has a similar relaxant role on airway smooth muscle (ASM) remains unknown. This study aimed to explore the relaxant property of AELL on ASM and the underlying mechanism.

Methods: Alkaloids were extracted from dried lotus leaves using the high temperature rotary evaporation extraction method. The effects of AELL on mouse ASM tension were studied using force measuring and patch-clamp techniques.

Results: It was found that AELL inhibited the high $\mathrm{K}^{+}$or acetylcholine chloride (ACh)-induced precontraction of mouse tracheal rings by $64.8 \pm 2.9 \%$, or $48.8 \pm 4.7 \%$, respectively. The inhibition was statistically significant and performed in a dose-dependent manner. Furthermore, AELL-induced smooth muscle relaxation was partially mediated by blocking voltage-dependent $\mathrm{Ca}^{2+}$ channels (VDCC) and non-selective cation channels (NSCC).
\end{abstract}

Conclusion: AELL, which plays a relaxant role in ASM, might be a new complementary treatment to treat abnormal contractions of the trachea and asthma.

Keywords: Asthma, Airway smooth muscle, Tracheal relaxation, Alkaloids, $\mathrm{Ca}^{2+}$ channel

\section{Background}

Respiratory disease is a severe health issue, it affects millions of people globally and is a serious burden for public healthcare [1]. Asthma and chronic obstructive pulmonary disease (COPD), two typical airway problems, have been linked to decreased quality of life, increased medical costs and even mortality and may be an underlying factor for lung cancer [2]. Airway smooth muscle (ASM), a particular cell type in the airway system, plays a vital role in airway obstruction during asthma and COPD. The dysfunction of ASM contributes to a series of cardinal symptoms in asthma and COPD, such as airway contractility, airway remodeling, and airway hyperresponsiveness [3-5]. Thus far, the pharmacological treatment of asthma and COPD mainly relies upon $\beta 2$ agonists and muscarinic antagonists, which can affect $\beta 2$-adrenergic and muscarinic receptors, respectively.

\footnotetext{
* Correspondence: qinghualiu95@163.com; shenjinhua2013@163.com ${ }^{\dagger}$ Equal contributors

${ }^{1}$ Institute for Medical Biology and Hubei Provincial Key Laboratory for Protection and Application of Special Plants in Wuling Area of China, College of Life Sciences, South-Central University for Nationalities, Wuhan 430074, China

Full list of author information is available at the end of the article
}

Through the regulation of signal pathways related to $G$ protein-coupled receptors, the reduction of intracellular calcium, and the subsequent opening of VDCC/NSCC, airway smooth muscle tone could be relaxed [6, 7]. However, numerous studies have indicated that currently available bronchodilators, especially $\beta 2$-agonists and muscarinic antagonists, have additive effects on safety, desensitization and tolerability [8-10]. Therefore, novel drugs are urgently needed for these airway diseases.

Recently, numerous traditional Chinese medicines (TCMs) have exhibited encouraging effects on a series of chronic diseases [11-15]. Additional evidence has shown that the effective constituents of TCMs may provide a new trend to explore potential bronchodilators for asthma and COPD [16-19]. Nelumbo nucifera, commonly called sacred lotus, is a perennial aquatic cash crop that is widely cultivated in Asia and Africa $[20,21]$. In China, the flowers, seeds, roots, leaves and rhizomes of lotus are extensively applied as ornamentation, drink, food, and as a medicinal herb [21, 22]. As a medicinal herb, different parts of this plant have exhibited diverse therapeutic benefits. In traditional therapy, lotus leaves are often listed as part of a healthy diet and 
are provided as a "tea drink" to improve lipid disorders, control blood pressure and lose weight. Several studies have explored the bioactive compounds extracted from lotus leaves, showing that they play more pharmacological roles in the treatment of diabetes, obesity, hyperuricemia, hepatic steatosis, lung cancer, HIV, etc. [22-29]. In our lab, a recent study showed that Plumula Nelumbinis, the green germ of Nelumbo nucifera, has been identified as providing relaxation effects in ASM [30]. Furthermore, nuciferine, a constituent of alkaloids extracted from lotus leaves, presents relaxation properties in rat mesenteric arteries [31]. Therefore, it was hypothesized that alkaloids extracted from lotus leaves can affect ASM reactivity.

To verify this hypothesis, the effects of alkaloids extracted from the leaves of Nelumbo nucifera were investigated in mouse ASM in the current study. The results show that high $\mathrm{K}^{+}$or $\mathrm{ACh}$-precontracted mouse ASM could be relaxed by AELL in a concentrationdependent manner. Further research indicates that AELL mediate relaxation through voltage-dependent $\mathrm{Ca}^{2+}$ channels (VDCC) and non-selective cation channels (NSCC) inhibition.

\section{Methods}

\section{Reagents and Chemicals}

Acetylcholine chlorides (ACh), Nifedipine, Niflumic acid (NA), and Tetraethylammonium chloride (TEA) were purchased from Sigma Chemical Co. (St. Louis, MO, USA). Other chemicals were purchased from Sinopharm Chemical Reagent Co. (Shanghai, China).

\section{Extraction of Alkaloids}

Dry Nelumbo nucifera leaves were bought from Tong-Ren-Tang (Hubei, China) and identified by Associated Prof. Hong Liu (South-Central University for Nationalities, Wuhan, China) and Prof. Ding-Rong Wan (South-Central University for Nationalities, Wuhan, China). The voucher specimen of this material has been deposited in the publicly available herbarium of South-Central University for Nationalities. The deposition number is SCUN201410023. 95\% ethanol were employed to enrich alkaloids in lotus leaves as previous described with some modification [32]. Briefly, lotus leaves (500 g) were air dried, pulverized and soaked in 95\% ethanol for $48 \mathrm{~h}$ at room temperature. The samples were subsequently extracted twice by heating reflux for $2 \mathrm{~h}$. The $\mathrm{pH}$ of pooled ethanol extracts was adjusted to $2-3$ with $0.5 \%$ hydrochloric acid. After filtering, $0.1 \mathrm{~mol} / \mathrm{L}$ sodium hydroxide was added into the acid solutions until the $\mathrm{pH}$ was 5-7. Subsequently, supernatants were collected and adjusted to $\mathrm{pH} 9-11$ with $0.1 \mathrm{~mol} / \mathrm{L}$ sodium hydroxide and diluted to $1 \mathrm{~L}$. The solution was then dried through rotary evaporation and vacuum filtered to yield AELL. The yield of AELL was $5.8 \%$ of raw material. Before experiments, AELL was dissolved with physiological saline solution (PSS) buffer (2 mM $\mathrm{CaCl}_{2}, 10 \mathrm{mM}$ Glucose, $10 \mathrm{mM}$ HEPES, $5 \mathrm{mM} \mathrm{KCl}$, $1 \mathrm{mM} \mathrm{MgCl}, 135 \mathrm{mM} \mathrm{NaCl}, \mathrm{pH}$ 7.4).

\section{Animals}

Six-week-old male BALB/c mice were purchased from the Hubei Provincial Center for Disease Control and Prevention (Wuhan, China). The mice were housed in a specific pathogen free (SPF) grade laboratory under a $12 \mathrm{~h}$ lightdark cycle with a stable temperature $\left(20-25{ }^{\circ} \mathrm{C}\right)$ and humidity (50-60\%). All mice animal experiments were approved and performed under the supervision of the Institutional Animal Care and Use Committee of the South-Center University for Nationalities. The license number is 2013-JS-2.

\section{Isometric Measurement of Tension}

Mouse ASM contraction was measured in tracheal rings as previously described [30]. Briefly, tracheas were isolated from cervically dislocated mice, and connective tissues were removed. Small tracheal rings $(\sim 5 \mathrm{~mm})$ were cut, and the resting tension was set to $0.5 \mathrm{~g}$ in a settled organ bath with PSS buffer. The experiment was initiated after the tracheal rings were equilibrated for $60 \mathrm{~min}$. Then, tracheal rings were precontracted with either $80 \mathrm{mM} \mathrm{K}^{+}$or $10^{-4} \mathrm{M}$ ACh for 3 times. Following an additional $30 \mathrm{~min}$ rest, the isometric tension was measured under the presence of $\mathrm{K}^{+}, \mathrm{ACh}$, or AELL. In the rinsing process, the trachea ring was thoroughly washed with PSS for 3 times $(5 \mathrm{~min}, 5 \mathrm{~min}, 50 \mathrm{~min}$, respectively) to remove AELL.

\section{Measurement of VDCC Currents}

Mouse ASM cells were isolated as previously described $[30,33,34]$. Whole-cell $\mathrm{Ba}^{2+}$ currents through VDCC were measured using an EPC-10 patch-clamp amplifier (HEKA, Lambrecht, Germany). The pipette solution containing $130 \mathrm{mM} \mathrm{CsCl}, 10 \mathrm{mM}$ EGTA, $10 \mathrm{mM}$ HEPES, $4 \mathrm{mM}$ Mg-ATP, $4 \mathrm{mM} \mathrm{MgCl}_{2}$, and $10 \mathrm{mM}$ TEA was adjusted to $\mathrm{pH} 7.2$ with $\mathrm{CsOH}$. The composition of the external solution was $27.5 \mathrm{mM} \mathrm{BaCl}, 11 \mathrm{mM}$ Glucose, $10 \mathrm{mM}$ HEPES, $1 \mathrm{mM} \mathrm{MgCl}$, $107 \mathrm{mM} \mathrm{NaCl}$, and $10 \mathrm{mM}$ TEA-Cl, which was adjusted to $\mathrm{pH} 7.4$ with $\mathrm{NaOH}$. ASM cells were patched and held at $-70 \mathrm{mV}$. The currents were measured following depolarization for $500 \mathrm{~ms}$ from -70 to $+40 \mathrm{mV}$ in $10 \mathrm{mV}$ increments every $30 \mathrm{~ms}$.

\section{Measurement of NSCC Currents}

The pipette solution for the measurement of NSCC currents containing $1 \mathrm{mM} \mathrm{CaCl}, 126 \mathrm{mM} \mathrm{CsCl,} 3 \mathrm{mM}$ EGTA, $10 \mathrm{mM}$ HEPES, and $1.2 \mathrm{mM} \mathrm{MgCl}_{2}$ was adjusted to $\mathrm{pH} 7.2$ with Tris. The free $\mathrm{Ca}^{2+}$ concentration was 
approximately $70 \mathrm{nM}$, as calculated using WEBMAXC STANDARD (http://www.stanford.edu/ cpatton/webmaxc/webmaxcS.htm). The bath solution was $\mathrm{K}^{+}$-free PSS (1.5 mM CaCl $2,11 \mathrm{mM}$ glucose, $10 \mathrm{mM}$ HEPES, $126 \mathrm{mM} \mathrm{NaCl}$ ) containing $100 \mu \mathrm{M} \mathrm{NA}, 10 \mu \mathrm{M}$ nifedipine, or $10 \mathrm{mM}$ TEA, which were employed to block $\mathrm{Cl}^{-}$, VDCC, or $\mathrm{K}^{+}$currents, respectively. ACh-induced NSCC currents were recorded with a ramp using a perforated whole-cell configuration from -80 to $+60 \mathrm{mV}$ over $500 \mathrm{~ms}$. The holding potential was $-60 \mathrm{mV}$.

\section{Statistical Analysis}

Statistical analysis and significance were measured with Student's t-test using Origin 9.0 software (OriginLab, Northampton, USA). The results are expressed as the means \pm SEM. In all comparisons, $p<0.05$ was considered statistically significant.

\section{Results}

\section{AELL Dose-dependently Inhibit High $\mathrm{K}^{+}$-induced Precontraction}

A high $\mathrm{K}^{+}$concentration causes the contraction of smooth muscle through the membrane depolarizationVDCC open-calcium influx pathway [35, 36]. The high $\mathrm{K}^{+}(80 \mathrm{mM})$-induced contraction was blocked by AELL in a dose-dependent manner (Fig. 1a, b). The maximal relaxation was $64.8 \pm 2.9 \%(n=8)$. The half-maximal inhibition $\left(\mathrm{IC}_{50}\right)$ was $7.28 \pm 1.4 \mathrm{mg} / \mathrm{mL}$. Moreover, after AELL washing out, the high $\mathrm{K}^{+}$-induced secondary contraction decreased significantly $(n=7)$ (Additional file 1: Figure S1A \& B). This result indicated AELL might have a long-term effect on precontracted ASM. Figure 1c and d showed that AELL $(17.8 \mathrm{mg} / \mathrm{mL})$ could relax a high $\mathrm{K}^{+}$-induced precontraction of ASM by $56.33 \% \pm 6.7 \%$. Nifedipine $(10 \mu \mathrm{M})$, which is a selective inhibitor of VDCC, completely blocked high $\mathrm{K}^{+}$-induced contraction (Fig. 1e). These results indicate that AELL-induced relaxation might be due to the inhibition of VDCC.

\section{AELL Block High $\mathrm{K}^{+}$-evoked $\mathrm{Ca}^{2+}$ Influx}

The blockage of VDCC was shown to relax ASM contraction via a decrease in intracellular $\mathrm{Ca}^{2+}$ [37]. To confirm this, the following experiments were performed. High $\mathrm{K}^{+}$-induced contraction under $\mathrm{Ca}^{2+}$-free conditions did not occur (Fig. 2a). Following the restoration of $\mathrm{Ca}^{2+}$, contraction immediately appeared and was greatly inhibited by AELL $(17.8 \mathrm{mg} / \mathrm{mL}$, Figure 2a). Meanwhile, ASM contraction induced by high $\mathrm{K}^{+}$-evoked $\mathrm{Ca}^{2+}$ influx was not obvious in the presence of $17.8 \mathrm{mg} / \mathrm{mL}$ AELL (Fig. 2b). These data suggest that AELL relax mouse ASM by the partial blockage of high $\mathrm{K}^{+}$-evoked $\mathrm{Ca}^{2+}$ influx.

\section{AELL Block VDCC Currents}

To further clarify the contribution of VDCC currents in the ability of AELL to relax ASM, the channel-mediated currents were measured with the whole-cell patch-clamp technique. As shown in Fig. 3a, the currents were

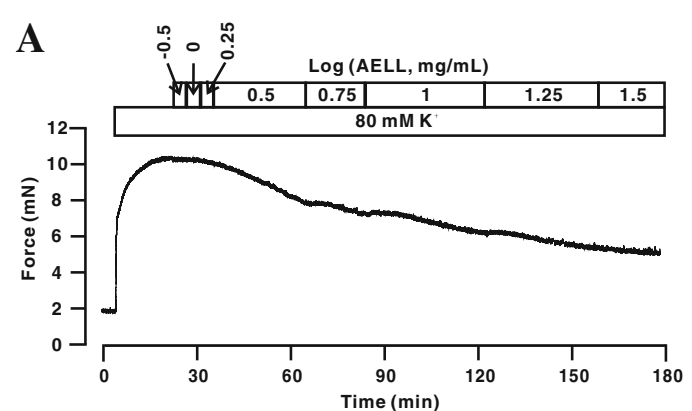

C

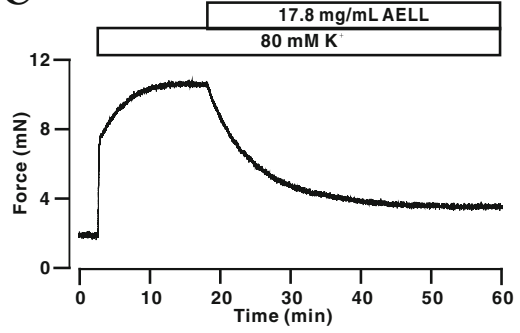

B

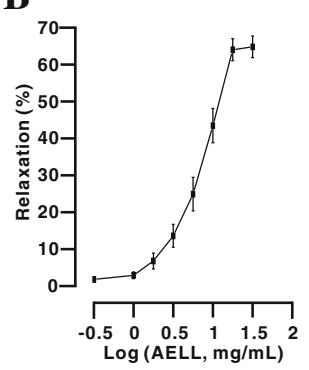

D

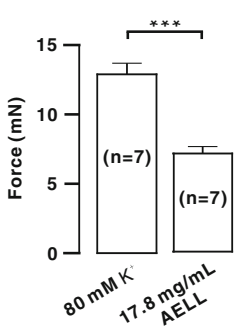

$\mathbf{E}$

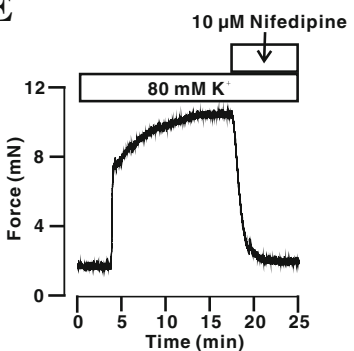

Fig. 1 AELL inhibits high $\mathrm{K}^{+}$-induced precontraction of mouse ASM. a High $\mathrm{K}^{+}$induced a contraction in a tracheal ring, which was gradually inhibited by AELL. b The same experiments were performed in 9 tracheal rings/9 mice, and a dose-relaxation curve was constructed. c \& $\mathbf{d}$ High $\mathrm{K}^{+}$-induced precontraction was inhibited by AELL $(17.8 \mathrm{mg} / \mathrm{mL})$, which was observed in 7 tracheal rings $/ 7$ mice. e The same contraction was blocked by nifedipine, a selective VDCC blocker. $(n=5)$. ${ }^{* *}$ represents $p<0.001$ 


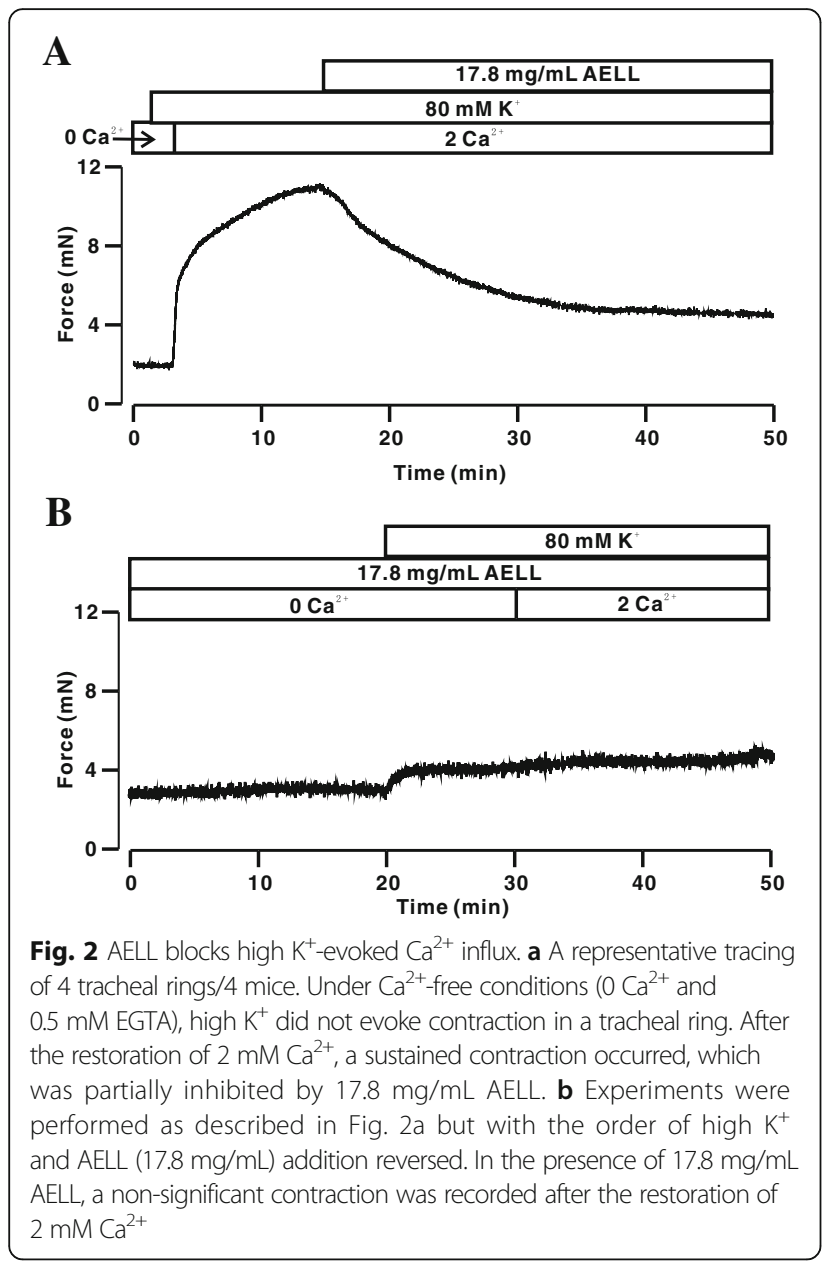

recorded from $-70 \mathrm{mV}$ to $+40 \mathrm{mV}$. The currents were eliminated by AELL (10 mg/mL) (Fig. 3b, top). As a positive control, the currents were blocked by nifedipine, indicating that they are VDCC currents (Fig. 3b, bottom). As a type of voltage-dependent channel, current-voltage $(I-V)$ curves were constructed $(n=6$, Fig. 3c). These results suggest that AELL inhibit VDCC currents.

\section{AELL Inhibit ACh-induced Precontraction}

As a particular muscarinic receptor agonist, ACh can induce the contraction of ASM through both VDCC and NSCC $[38,39]$. As shown in Fig. 4a, AELL could relax ACh-induced precontraction in a dose-dependent manner. A relaxation curve was calculated, and the maximal relaxation was $48.8 \pm 4.7 \%$ (Fig. $4 \mathrm{~b}$ ). As shown in Additional file 1: Figure S1C \& D, the ACh-induced contraction could not recover after AELL washing out $(n=6)$. Furthermore, to identify the role of NSCC, VDCC was blocked with nifedipine. The precontraction was subtly blocked by nifedipine $(10 \mu M)$. Subsequently, the isolated tension was mostly eliminated by AELL (31.6 mg/mL) (Fig. 4c). In Fig. 4d, the bar graph shows that the maximal inhibition by nifedipine and AELL was $13.32 \pm 3.8 \%$ and $48.47 \pm 1.8 \%$ $(n=5)$, respectively. These experiments indicate that in addition to VDCC, NSCC might also be involved in AELL-induced relaxation.

\section{AELL Block ACh-evoked $\mathrm{Ca}^{2+}$ Influx}

To investigate the role of NSCC in AELL-induced relaxation, $\mathrm{Ca}^{2+}$ influx was measured under $\mathrm{ACh}$ precontraction (Fig. 5). As shown in Fig. 5, ACh induced a

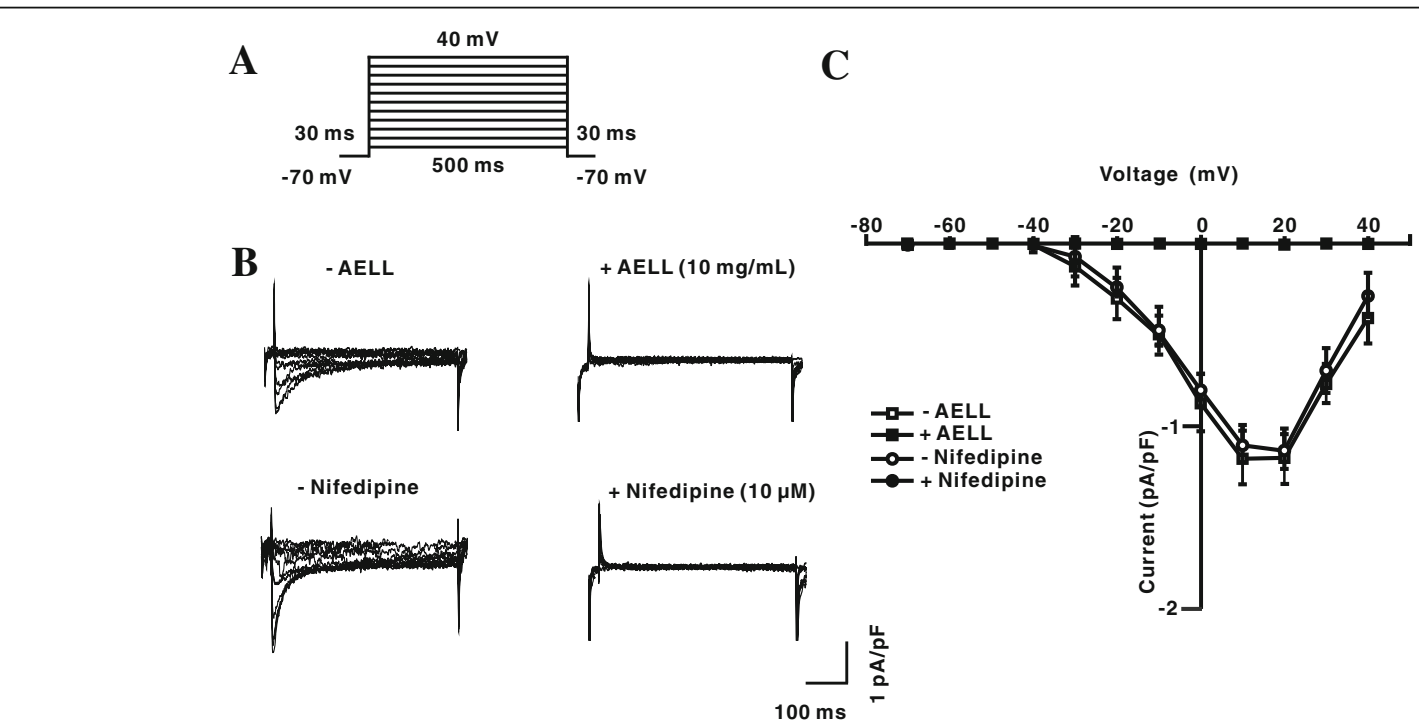

Fig. 3 AELL blocks VDCC currents. a Measurement of VDCC currents following a range from $-70 \mathrm{mV}$ to $40 \mathrm{mV}$. b VDCC currents were recorded following depolarization, which were blocked by AELL or nifedipine. c I-V relationship was constructed based on the results of 5 to 6 experiments 

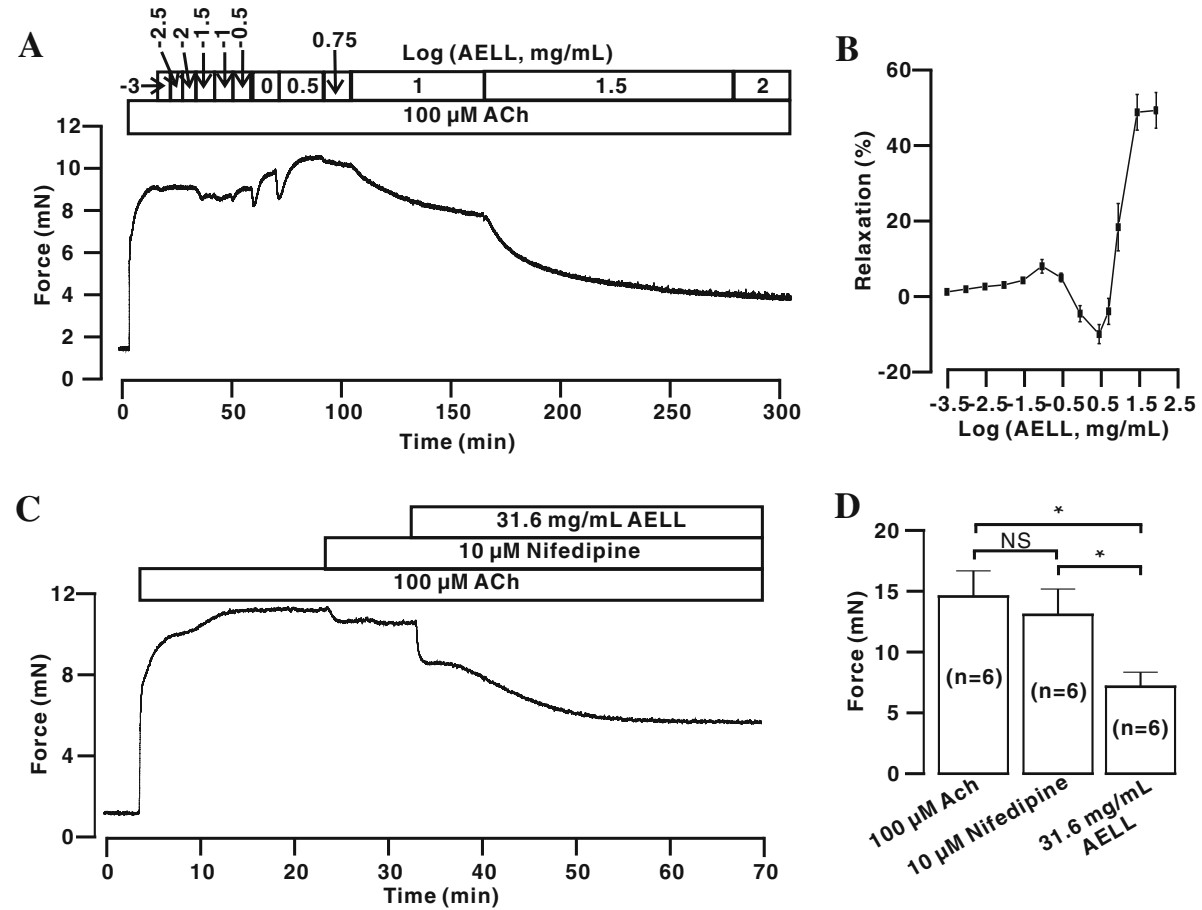

Fig. 4 AELL inhibits ACh-induced precontraction of mouse ASM. a ACh induced a steady-state contraction in a mouse tracheal ring, which was inhibited by AELL in a concentration-dependent manner. $\mathbf{b}$ Dose-relaxation curve of AELL based on the results of 7 different experiments shown in (a). c ACh induced a steady contraction even in the presence of nifedipine; however, it was partially inhibited by AELL. $\mathbf{d}$ Comparison of the relaxant effects of nifedipine and AELL on ACh-induced contraction. NS represents no significance. * represents $p<0.05$

transient contraction in the presence of nifedipine $(10 \mu \mathrm{M})$ and $\mathrm{Ca}^{2+}$-free conditions, which indicates a transient release of intracellular calcium. The addition of $2 \mathrm{mM} \mathrm{Ca}^{2+}$ triggered a sustained contraction that was partially blocked $(61.8 \pm 6.1 \%)$ by $31.6 \mathrm{mg} / \mathrm{mL}$ AELL. These data indicate that AELL inhibit the nifedipineresistant $\mathrm{Ca}^{2+}$ influx through NSCC.

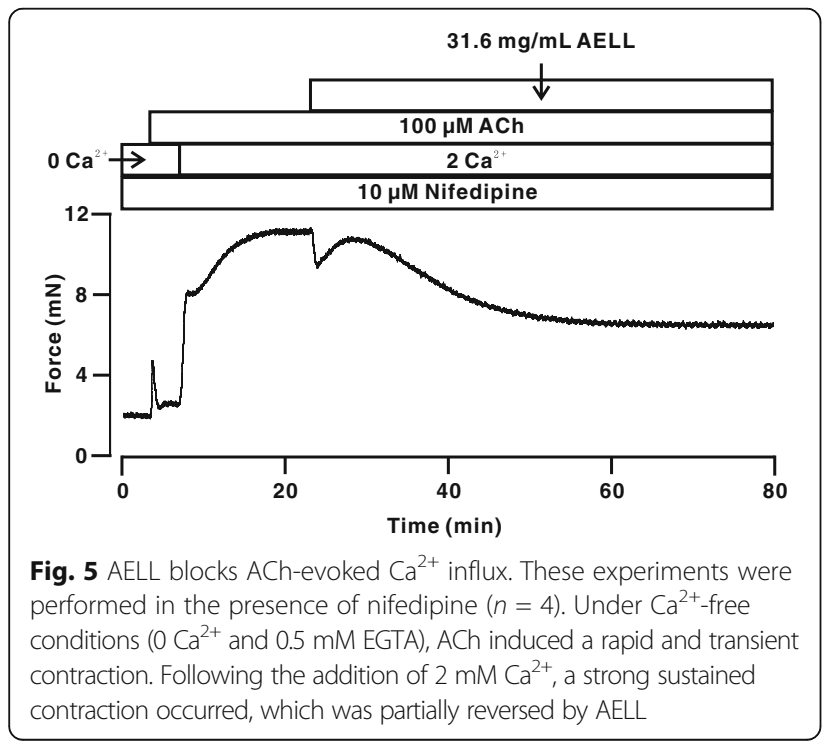

\section{AELL Inhibit NSCC Currents}

To test whether AELL have some effects on NSCC currents, ACh-activated NSCC currents were measured in the presence or absence of AELL. To isolate NSCC currents, nifedipine, NA and TEA were employed to block currents from VDCC, $\mathrm{Cl}^{-}$channels and $\mathrm{K}^{+}$channels, respectively (Fig. 6a). The results show that NSCC currents were completely blocked by AELL (Fig. 6b). Three representative ramp current traces at time points $\mathrm{a}, \mathrm{b}$, and $\mathrm{c}$ are shown in Fig. 6c. The mean values of the current amplitudes at $-70 \mathrm{mV}$ were $-15.6 \pm 0.5 \mathrm{pA}$ and $-7.5 \pm 0.5 \mathrm{pA}$ at time points $\mathrm{b}$ and $\mathrm{c}$, respectively ( $n=6$, Fig. $6 \mathrm{~d}$ ). Taken together, AELL can inhibit ACh-induced NSCC currents.

\section{Discussion}

As an alternative medicine, the TCM herb has been integrated into orthodox therapies for several chronic diseases associated with the dysfunction of smooth muscles $[15,40]$. Furthermore, multiple bioactive constituents from TCM herbs have been identified to have relaxation properties on excessively contractive ASM, which could be complementary therapies for chronic respiratory diseases, especially asthma and COPD [30, 41-46]. In the current study, the relaxant effects of AELL, an alcoholic extraction of Nelumbo 

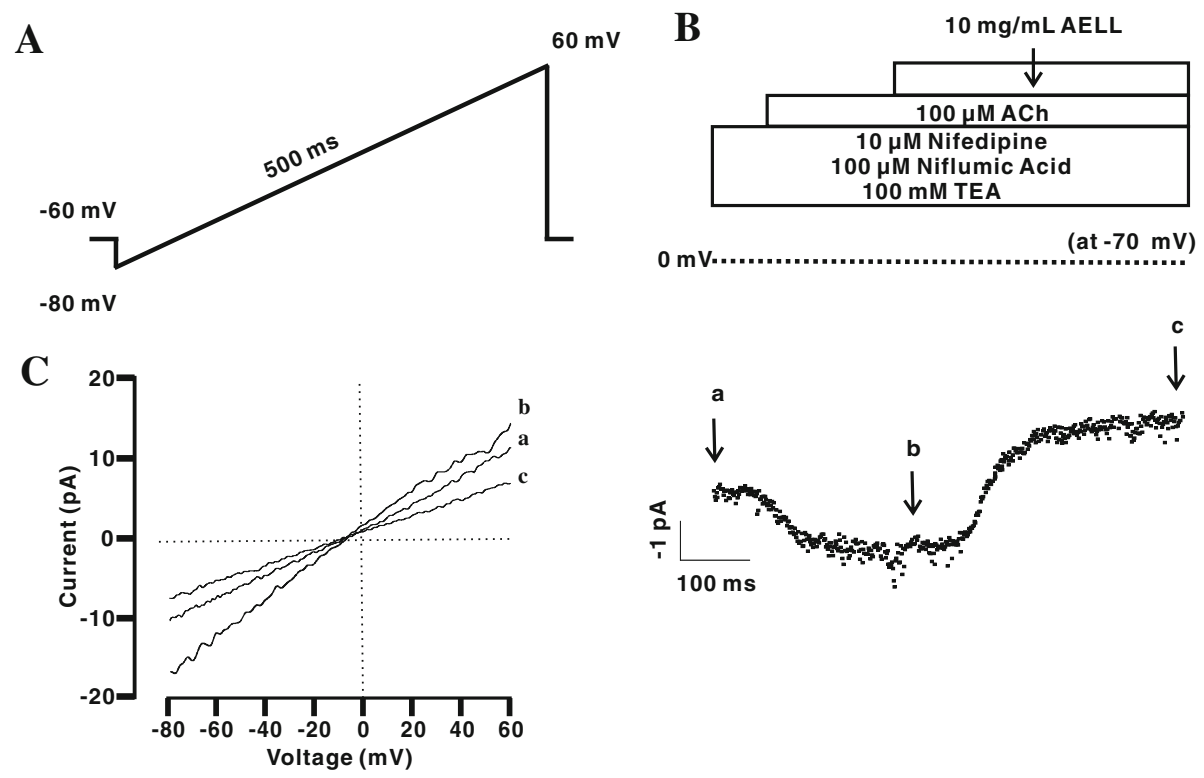

Fig. 6 AELL blocks NSCC currents. a The protocol used to measure NSCC currents in single ASM cells. b 1 - $t$ relationships were recorded at $\mathrm{Vm}=-70 \mathrm{mV}$, which indicated that ACh-induced NSCC currents was completely blocked by AELL. c The slope currents at time points a, b, and c in (b)

nucifera leaves, on mouse ASM tone and the underlying electrophysiological mechanisms were explored.

In current asthma therapy, $\beta 2$-agonists and muscarinic antagonists are two regular bronchodilators, which can result in a quick and lasting relaxant effect. Voltagedependent calcium channel (VDCC) is involved in $\beta 2$-agonist-induced tracheal relaxation $[47,48]$, while VDCC and NSCC both play important roles in muscarinic antagonist-induced ASM relaxation [38, 39]. A high $\mathrm{K}^{+}$concentration causes the contraction of ASM by increasing the intracellular $\mathrm{Ca}^{2+}$ concentration, which is induced by plasma membrane depolarization and VDCC activation [35, 36]. ACh, one of the most important neurotransmitters, causes the contraction of ASM by simulating the muscarinic3 receptor, evoking $\mathrm{Ca}^{2+}$ influx, which is induced by both VDCC and NSCC opening $[38,39]$. Therefore, in the current study, high $\mathrm{K}^{+}$and ACh were employed to stimulate a contractile response in asthma.

It was first investigated whether AELL can relax precontracted ASM by high $\mathrm{K}^{+}$or ACh stimulation (Figs. 1 and 4). It was found that AELL could partially relax high $\mathrm{K}^{+} / \mathrm{ACh}$-precontracted mouse ASM in a dose-dependent way, and the maximum efficiency of relaxation was approximately 50\%. Furthermore, AELLinduced relaxation attained its maximum relaxant effect in $10 \mathrm{~min}$ and lasted for hours. All the data confirm that AELL have relaxation characteristics that are similar to those of current bronchodilators.

To further explore the mechanism of AELL-induced relaxation, $\mathrm{Ca}^{2+}$ influx and VDCC/NSCC channel currents were studied. Increased $\mathrm{Ca}^{2+}$ influx is essential in both high $\mathrm{K}^{+}$and Ach-induced precontraction. Experiments of AELL-induced relaxation were performed with or without $\mathrm{Ca}^{2+}$-involved conditions (Figs. 2 and 5). It was found that the relaxant characteristics of AELL were implemented through the inhibition of extracellular $\mathrm{Ca}^{2+}$ influx. Although ACh could evoke a transient contraction with intracellular $\mathrm{Ca}^{2+}$ release from the sarcoplasmic reticulum as shown in Fig. 5, a sustained contraction occurred only with an extracellular solution including $2 \mathrm{mM}$ $\mathrm{Ca}^{2+}$. The results indicate that intracellular calcium influx is indispensable in AELL-induced relaxation.

To demonstrate the roles of VDCC and NSCC in AELL-induced relaxation, VDCC or NSCC currents were measured. It was found that AELL could completely inhibit both VDCC and NSCC currents (Figs. 3 and 6). Considering that AELL did not completely relax high $\mathrm{K}^{+}$or $\mathrm{ACh}$-induced precontraction while VDCC and NSCC currents were both completely blocked, unknown pathways might be involved in AELLinduced relaxation in addition to VDCC and NSCC.

Taken together, our study shows that AELL, an alcoholic extraction of lotus leaves, presents an integrated characteristic of $\beta 2$-agonists and muscarinic antagonists to relax mouse ASM. Similar to the relaxant mechanism of a regular bronchodilator, $\mathrm{Ca}^{2+}$ influx was inhibited, and both VDCC and NSCC were inactivated in AELLinduced relaxation.

The results illuminate the pharmacological characteristics of AELL, which might be a complementary treatment or even an emerging bronchodilator for application in 
respiratory diseases. However, it should be noted that $17.8 \mathrm{mg} / \mathrm{mL}$ or $31.6 \mathrm{mg} / \mathrm{mL}$ AELL were employed in the experiment. As a crude extract, the effective component of AELL was unclear. We supposed that the proportion of active ingredient in AELL is not enough to induce a complete relaxation. Meanwhile, some contents of AELL may play a contractive other than relaxant role in ASM. It was also mentioned that the contraction of ASM was hard to recover after rinsing, which indicated that the crude extract might have a high affinity and hard to be totally washed out. However, the type of AELL-induced inhibition (competitive or non-competitive) needs to be further confirmed.

Overall, two issues remain to be resolved. 1. As a crude ethanol extraction, the effective ingredients of AELL are still unknown. Recent studies have revealed that the major constituents of AELL are aporphine alkaloids [49]. Nuciferine, a vital constituent of aporphine alkaloids, had a pharmacologic profile of action associated with arterial relaxation via suppressing extracellular calcium influx [31], which indicates that nuciferine may play an important role in AELL-induced respiratory relaxation and the underlying mechanism needs to be further explored. 2 . The partially relaxant characteristics of AELL imply that an unknown pathway might be involved, and the complex intracellular signaling mechanisms require further elucidation.

\section{Conclusion}

AELL directly or indirectly blocked VDCC and NSCC, then reduced calcium influx, and finally relaxed ASM. The exact mechanism of action and the phytochemistry of AELL will be investigated in future studies.

\section{Additional file}

Additional file 1: Figure S1. The influence of AELL on ASM. (A) \& (B) With AELL washing out, high $\mathrm{K}^{+}$-induced contraction was decreased obviously. (C) \& (D) When AELL removed, ACh-induced contraction was decreased obviously, too. (PDF 29 kb)

\section{Abbreviations}

ACh: Acetylcholine chlorides; AELL: Alkaloids extracted from lotus leaves; ASM: Airway smooth muscle; COPD: Chronic obstructive pulmonary disease; LCPSS: Low-Ca ${ }^{2+}$ physiological saline solution; NA: Niflumic acid; NSCC: Nonselective cation channels; PSS: Physiological saline solution; SPF: Specific pathogen free; TCM: Traditional Chinese medicine; TEA: Tetraethylammonium chloride; VDCC: Voltage-dependent $\mathrm{Ca}^{2+}$ channels

\section{Acknowledgements}

The authors gratefully acknowledge all the fellows in Institute for Medical Biology, College of Life Sciences, South-Central University for Nationalities. We also gratefully thanks for the professional advice from Dr. Hong Liu and Dr. Ding-Rong Wan.

\section{Funding}

This project was supported by the Fund for Distinguished Young Scholars of Hubei Province to Jinhua Shen (Grant No. 2012FFA028), the National Natural Science Foundation of China (Grant No. 81170227 to Jinhua Shen, 31,101,047 to Lu Xue), and the Natural Science Foundation of Hubei Province, China (Grant No. 2014CFB232), to Lu Xue.

\section{Availability of data and materials}

The data and materials supporting the conclusions are included within the article and its supplementary information files.

\section{Authors' contributions}

LX, CC, QHL and JS conceived and designed the experiments. LX, XY, QZ, CC and JS performed the experiments. XY, QZ, CC and JS analyzed the data and generated the Figures. CC, QHL, LX, and JS wrote the manuscript. All authors gave final approval for the submitted version.

\section{Competing Interests}

The authors declare that they have no competing interests.

\section{Consent for publication}

Not applicable.

\section{Ethics approval}

All methods applied in current study are in accordance with protocols approved by the South-Central University for Nationalities. All mice animal experiments were approved and performed under the supervision of the Institutional Animal Care and Use Committee of the South-Central University for Nationalities.

\section{Publisher's Note}

Springer Nature remains neutral with regard to jurisdictional claims in published maps and institutional affiliations.

\section{Author details}

${ }^{1}$ Institute for Medical Biology and Hubei Provincial Key Laboratory for Protection and Application of Special Plants in Wuling Area of China, College of Life Sciences, South-Central University for Nationalities, Wuhan 430074, China. 'Wuhan Youzhiyou Biopharmaceutical Co., Ltd., 666 Gaoxin Road, Biolake, Wuhan 430075, China.

Received: 23 June 2016 Accepted: 10 March 2017

Published online: 20 March 2017

\section{References}

1. Vos T, Barber R, Bell B, Bertozzi-Villa A, Biryukov S, Bolliger I, Charlson F, Davis A, Degenhardt L, Dicker D, et al. Global, regional, and national incidence, prevalence, and years lived with disability for 301 acute and chronic diseases and injuries in 188 countries, 1990-2013: a systematic analysis for the Global Burden of Disease Study 2013. Lancet. 2015;386:743-800.

2. Mateu-Jimenez M, Sanchez-Font A, Rodriguez-Fuster A, Aguilo R, Pijuan L, Fermoselle C, Gea J, Curull V, Barreiro E. Redox Imbalance in Lung Cancer of Patients with Underlying Chronic Respiratory Conditions. Mol Med. 2016

3. An SS, Bai TR, Bates JH, Black JL, Brown RH, Brusasco V, Chitano P, Deng L, Dowell M, Eidelman DH, et al. Airway smooth muscle dynamics: a common pathway of airway obstruction in asthma. Eur Respir J. 2007;29:834-60.

4. Hershenson MB, Brown M, Camoretti-Mercado B, Solway J. Airway smooth muscle in asthma. Annu Rev Pathol. 2008;3:523-55.

5. West AR, Syyong HT, Siddiqui S, Pascoe CD, Murphy TM, Maarsingh H, Deng L, Maksym GN, Bosse Y. Airway contractility and remodeling: links to asthma symptoms. Pulm Pharmacol Ther. 2013;26:3-12.

6. Kume H, Fukunaga K, Oguma T. Research and development of bronchodilators for asthma and COPD with a focus on $\mathrm{G}$ protein/KCa channel linkage and beta2-adrenergic intrinsic efficacy. Pharmacol Ther. 2015;156:75-89.

7. Panettieri Jr RA. Bronchodilators, receptors and cross-talk: Together is better? Postgrad Med. 2015;127:771-80

8. Hu Y, Cantarero-Arevalo L. Ethnic differences in adverse drug reactions to asthma medications: a systematic review. J Asthma. 2016;53:69-75. 
9. Gupta P, O'Mahony MS. Potential adverse effects of bronchodilators in the treatment of airways obstruction in older people: recommendations for prescribing. Drugs Aging. 2008;25:415-43.

10. Cazzola M, Matera MG. Bronchodilators: current and future. Clin Chest Med. 2014:35:191-201.

11. Xie W, Du L. Diabetes is an inflammatory disease: evidence from traditional Chinese medicines. Diabetes Obes Metab. 2011;13:289-301.

12. Wang BE. Treatment of chronic liver diseases with traditional Chinese medicine. J Gastroenterol Hepatol. 2000;15(Suppl):E67-70.

13. Cai $Y$, Luo Q, Sun $M$, Corke $H$. Antioxidant activity and phenolic compounds of 112 traditional Chinese medicinal plants associated with anticancer. Life Sci. 2004;74:2157-84.

14. Jiang WY. Therapeutic wisdom in traditional Chinese medicine: a perspective from modern science. Trends Pharmacol Sci. 2005;26:558-63.

15. Xiong $X$, Yang $X$, Liu Y, Zhang Y, Wang P, Wang J. Chinese herbal formulas for treating hypertension in traditional Chinese medicine: perspective of modern science. Hypertens Res. 2013;36:570-9.

16. Tagaya E, Tamaoki J, Kawatani K, Taira M, Nagai A. Inhibition of airway smooth muscle tone by Chinese herbal medicines. Eur Respir J. 2000;16:1123-8.

17. Li XM, Huang CK, Zhang TF, Teper AA, Srivastava K, Schofield BH, Sampson HA. The chinese herbal medicine formula MSSM-002 suppresses allergic airway hyperreactivity and modulates $\mathrm{TH} 1 / \mathrm{TH} 2$ responses in a murine model of allergic asthma. J Allergy Clin Immunol. 2000;106:660-8.

18. Hsieh $\mathrm{KH}$. Evaluation of efficacy of traditional Chinese medicines in the treatment of childhood bronchial asthma: clinical trial, immunological tests and animal study. Taiwan Asthma Study Group. Pediatr Allergy Immunol. 1996;7:130-40.

19. Li XM, Brown L. Efficacy and mechanisms of action of traditional Chinese medicines for treating asthma and allergy. J Allergy Clin Immunol. 2009;123:297-306. quiz 7-8

20. Wu S, Sun C, Cao X, Zhou H, Hong Z, Pan Y. Preparative counter-current chromatography isolation of liensinine and its analogues from embryo of the seed of Nelumbo nucifera GAERTN. using upright coil planet centrifuge with four multilayer coils connected in series. J Chromatogr A. 2004;1041:153-62.

21. Mukherjee PK, Mukherjee D, Maji AK, Rai S, Heinrich M. The sacred lotus (Nelumbo nucifera) - phytochemical and therapeutic profile. J Pharm Pharmacol. 2009;61:407-22.

22. Ma C, Li G, He Y, Xu B, Mi X, Wang H, Wang Z. Pronuciferine and nuciferine inhibit lipogenesis in 3T3-L1 adipocytes by activating the AMPK signaling pathway. Life Sci. 2015;136:120-5.

23. Liu CM, Kao CL, Wu HM, Li WJ, Huang CT, Li HT, Chen CY. Antioxidant and anticancer aporphine alkaloids from the leaves of Nelumbo nucifera Gaertn. cv. Rosa-plena. Molecules. 2014;19:17829-38.

24. Kashiwada Y, Aoshima A, Ikeshiro Y, Chen YP, Furukawa H, Itoigawa M, Fujioka T, Mihashi K, Cosentino LM, Morris-Natschke SL, et al. Anti-HIV benzylisoquinoline alkaloids and flavonoids from the leaves of Nelumbo nucifera, and structure-activity correlations with related alkaloids. Bioorg Med Chem. 2005;13:443-8

25. Ohkoshi E, Miyazaki H, Shindo K, Watanabe H, Yoshida A, Yajima H. Constituents from the leaves of Nelumbo nucifera stimulate lipolysis in the white adipose tissue of mice. Planta Med. 2007;73:1255-9.

26. Ono $Y$, Hattori E, Fukaya $Y$, Imai S, Ohizumi Y. Anti-obesity effect of Nelumbo nucifera leaves extract in mice and rats. J Ethnopharmacol. 2006;106:238-44.

27. Nguyen KH, Ta TN, Pham TH, Nguyen QT, Pham HD, Mishra S, Nyomba BL. Nuciferine stimulates insulin secretion from beta cells-an in vitro comparison with glibenclamide. J Ethnopharmacol. 2012;142:488-95.

28. Liu W, Yi DD, Guo JL, Xiang ZX, Deng LF, He L. Nuciferine, extracted from Nelumbo nucifera Gaertn, inhibits tumor-promoting effect of nicotine involving Wnt/beta-catenin signaling in non-small cell lung cancer. J Ethnopharmacol. 2015;165:83-93.

29. Lee JS, Shukla S, Kim JA, Kim M. Anti-angiogenic effect of Nelumbo nucifera leaf extracts in human umbilical vein endothelial cells with antioxidant potential. PLoS One. 2015;10:e0118552.

30. Tan L, Chen W, Wei MY, Shen J, Yu MF, Yang G, Guo D, Qin G, Ji G, Liu QH. Relaxant action of plumula nelumbinis extract on mouse airway smooth muscle. Evid Based Complement Alternat Med. 2015;2015:523640.

31. Wang X, Cheang WS, Yang H, Xiao L, Lai B, Zhang M, Ni J, Luo Z, Zhang Z, Huang $Y$, et al. Nuciferine relaxes rat mesenteric arteries through endothelium-dependent and -independent mechanisms. Br J Pharmacol. 2015;172:5609-18.
32. Ma W, Lu Y, Hu R, Chen J, Zhang Z, Pan Y. Application of ionic liquids based microwave-assisted extraction of three alkaloids $\mathrm{N}$-nornuciferine, $\mathrm{O}$ nornuciferine, and nuciferine from lotus leaf. Talanta. 2009;80:1292-7.

33. Zhang T, Luo XJ, Sai WB, Yu MF, Li WE, Ma YF, Chen W, Zhai K, Qin G, Guo $D$, et al. Non-selective cation channels mediate chloroquine-induced relaxation in precontracted mouse airway smooth muscle. PLoS One. 2014; 9:e101578.

34. Liu QH, Zheng YM, Korde AS, Yadav VR, Rathore R, Wess J, Wang YX. Membrane depolarization causes a direct activation of $\mathrm{G}$ protein-coupled receptors leading to local Ca2+ release in smooth muscle. Proc Natl Acad Sci U S A. 2009:106:11418-23.

35. Karaki H, Urakawa N, Kutsky P. Potassium-induced contraction in smooth muscle. Nihon Heikatsukin Gakkai zasshi. 1984;20:427-44.

36. Karaki H, Ozaki H, Hori M, Mitsui-Saito M, Amano K, Harada K, Miyamoto S, Nakazawa H, Won KJ, Sato K. Calcium movements, distribution, and functions in smooth muscle. Pharmacol Rev. 1997;49:157-230.

37. Coelho RR, Souza EP, Soares PM, Meireles AV, Santos GC, Scarparo HC, Assreuy AM, Criddle DN. Effects of chloride channel blockers on hypotonicity-induced contractions of the rat trachea. Br J Pharmacol. 2004;141:367-73.

38. Fleischmann BK, Wang YX, Kotlikoff MI. Muscarinic activation and calcium permeation of nonselective cation currents in airway myocytes. Am J Phys. 1997;272:C341-9.

39. Wang YX, Fleischmann BK, Kotlikoff MI. M2 receptor activation of nonselective cation channels in smooth muscle cells: calcium and $\mathrm{Gi} / \mathrm{G}(0)$ requirements. Am J Phys. 1997:273:C500-8.

40. Ziment I, Tashkin DP. Alternative medicine for allergy and asthma. J Allergy Clin Immunol. 2000;106:603-14.

41. Ge YB, Dai Q, Wan DR, Liu QH, Mei ZN. Relaxant effect of 1-butanol fraction from Elaeagnus pungens leaf through inhibiting L-type Ca2+ channel on guinea pig tracheal smooth muscle. J Ethnopharmacol. 2013;150:196-201.

42. Townsend EA, Emala $\mathrm{Sr}$ CW. Quercetin acutely relaxes airway smooth muscle and potentiates beta-agonist-induced relaxation via dual phosphodiesterase inhibition of PLCbeta and PDE4. American Journal of Physiology Lung Cellular and Molecular Physiology. 2013;305:L396-403.

43. Townsend EA, Zhang Y, Xu C, Wakita R, Emala CW. Active components of ginger potentiate beta-agonist-induced relaxation of airway smooth muscle by modulating cytoskeletal regulatory proteins. Am J Respir Cell Mol Biol. 2014;50:115-24.

44. Townsend EA, Siviski ME, Zhang Y, Xu C, Hoonjan B, Emala CW. Effects of ginger and its constituents on airway smooth muscle relaxation and calcium regulation. Am J Respir Cell Mol Biol. 2013;48:157-63.

45. Yang N, Liang B, Srivastava K, Zeng J, Zhan J, Brown L, Sampson H, Goldfarb J, Emala C, Li XM. The Sophora flavescens flavonoid compound trifolirhizin inhibits acetylcholine induced airway smooth muscle contraction. Phytochemistry. 2013;95:259-67.

46. Yue GG, Chan KM, To MH, Cheng L, Fung KP, Leung PC, Lau CB. Potent airway smooth muscle relaxant effect of cynatratoside $B$, a steroidal glycoside isolated from Cynanchum stauntonii. J Nat Prod. 2014;77:1074-7.

47. Gilani AH, Khan AU, Jabeen Q, Subhan F, Ghafar R. Antispasmodic and blood pressure lowering effects of Valeriana wallichii are mediated through K+ channel activation. J Ethnopharmacol. 2005;100:347-52.

48. Soder RP, Petkov GV. Large conductance Ca2+-activated K+ channel activation with NS1619 decreases myogenic and neurogenic contractions of rat detrusor smooth muscle. Eur J Pharmacol. 2011:670:252-9.

49. Ma C, Wang J, Chu H, Zhang X, Wang Z, Wang H, Li G. Purification and Characterization of Aporphine Alkaloids from Leaves of Nelumbo nucifera Gaertn and Their Effects on Glucose Consumption in 3T3-L1 Adipocytes. Int J Mol Sci. 2014:15:3481-94. 